\title{
Flexible Manufacturing Systems Scheduling: A Systematic Review
}

\author{
Vivekanand S. Gogi and Dr.K.S. Badarinarayana
}

\begin{abstract}
Flexible manufacturing system, the word is simple to understand but indeed difficult to achieve. Many firms failed to achieve flexible manufacturing system, become history and firms who effectively achieved it, have pioneered themselves in manufacturing industry. The ultimate need to flexible manufacturing system arises from very basic rule of environment, nothing is permanent. The changing needs, choices, priorities and preferences of business or its stakeholder dynamic behaviour forces firms to be flexible enough to deliver what is required. A manufacturing company needs flexibility and system utilization for its high level of throughput. This review study emphasizes some of the major contributions to the flexible manufacturing system and recent development in the field. The study enfolds major components of flexible manufacturing system namely automatic guided vehicles (AGV), Scheduling, artificial neural network and simulation modeling.
\end{abstract}

Keywords--- Automatic Guided Vehicles (AGV), Scheduling, Artificial Intelligence and Simulation Modeling

\section{INTRODUCTION}

A $\mathrm{N}$ Efficient production techniques for a wide variety of part types uses Flexible manufacturing systems (FMS). The automated guided vehicle uses material transportation technique as their application. For the complexity of the job, scheduling and automated guided vehicles play an important role. Increased efficiency needs proper planning and operations of flexible manufacturing system. The problems that the researches find most of them are material handling and vehicle scheduling. The following review is on machines as well as on automated guided vehicles.

This review explores the following broad aspects of FSM:

i. Automated Guided Vehicles: Its evolution and scheduling rules.

ii. Part type selection and its effect on scheduling.

iii. Scheduling and its batch size changes.

iv. Artificial neural networks: Its application in the evolution of flexible manufacturing systems.

v. Simulation modelling: Its application in the evolution of flexible manufacturing systems.

Flexible manufacturing systems (FMS) will have an automated material handling system, a part fixture, storage system, human operator workstations and computer numerical

Vivekanand S. Gogi, Research Scholar, VTU, Assistant Professor, Dept. of IEM, $R \quad V$ College of Engineering, Bengaluru, India. E-mail:vivekanands@rvce.edu.in

Dr.K.S. Badarinarayana, Principal, MS Engineering College, Bengaluru, India.E-mail:principal@msec.ac.in

DOI: 10.9756/BIJIEMS.10455 controlled (CNC). Perfect planning is necessary for achieving operational efficiency and can be achieved by adapting the FMS's flexibility. CNC machines are used to optimize the parts flow for an material handling systems and central control computer for machine flow.

\section{Systematic ReVieW}

Mathematical algorithms are created and applied for scheduling problems by a large number of researchers. Specific FMS configuration and the objective is to optimize FMS is dealt by Udhayakumar and Kumanan 2010. The analysis of material handling and its performance are studied by Devikar et al. 2010, the part launching and sequencing decisions are studied by Joseph and Sridharan 2009, Wadhwa, Singholi and Prakash 2009 on the control strategies methodology evaluation, tool assessment algorithms have been developed by Quiroga, Ciorciari and Rossetti 2007. Planning, scheduling capability and their increasing type of dynamics in nature of manufacturing are seen as their focus by the authors Drake, Smith, and Peters 1995.

Flexible manufacturing systems (FMS) operations literature based on the methodology can be classified in the following ways:

1. Approach based on Simulation: Discrete event simulation as a scheduling tool has been described by recent authors. Simulation is as a tool to evaluate the dispatching rules. A production system model was built and tested for the exact current state of the industry. Mathematical programming formulations does not give more yield as that of simulation model for an FMS operating problems. Simulation tool has been used for decision support as well as to bridge the gap in the real world situations.

2. Approach based on Artificial Intelligence(AI): Artificial Intelligence is used for the operation problems of FMS. AI involved to develop problems having large search space. AI uses two techniques namely expert system and planning. Planning, also called problem solving, concerns itself with situations where there is a goal, and different actions have to be planned to achieve the goal, such goals are achieved by having different actions of plan. AI techniques are helpful for general purpose problems and for case studies in FMS operations, desirability. 
3. Approach based on Automatic Guided vehicles: The scheduling problems are complex in nature and they will not work according to the requirement of the flexible manufacturing system elements. Therefore the application of automated guided vehicles comes into the picture. The Automatic Guided vehicles are equipped to help the production, storage equipment with controlled intelligent system. In sophisticated manufacturing plant, the application of Automatic Guided vehicles is increasing enormously for material transfer in any production lines. The automation technology is in the front run for increasing productivity as well as for flexibility of any integrated manufacturing environment. In this regard a fully designed and efficiently managed material handling system is required. The application of automated guided vehicle for any material handling, is increasing rapidly. For the purpose of path selection and its positiong the automated guided vehicles are equipped with battery and a program for the movement of unmanned vehicles. The AGV's are frequently used for the applications of changing transport patterns.

\section{BENEFITS AND Issues Associated with FMS}

Increase in machine utilization is one of the benefit of FMS when number of machines are less. FMS also reduces inventory requirement and labour requirement at greater context under the given circumstances. The consequence of lower number machine and labour requirement ensures shorter manufacturing lead time which will further yield high productivity. One in a other way FMS provides some key benefits but however they can be achieved at a certain cost, so it will be management decision to combat right level of flexibility with available resources.

The literature survey reveals some conflicts associated with FSM, some key issues found during the survey are effective management of production volume, variations in process routing and availability of storage capacity. FSM also requires efficient scheduling and dispatching mechanism to handle the moments of goods. Further challenge is der to manage tools available effectively and also their allocation to the processes.

\section{CONCLUSION AND FUtURE SCOPE}

To provide a better solutions to scheduling and control problems, the literature of FMS has provided the base for further research. The methodologies are to be developed for the use in control systems, which are otherwise more complex in nature. Research has to be developed in scheduling and control problems area where more human input into the loop is to be adopted. Researchers have to take interest in developing control systems which take responsibility of complexity of interaction of multiple resource in an flexible manufacturing systems. To evaluate control policies, heuristics, simulation can be used as an model for Flexible manufacturing systems. A simulation model can be made use of to create a model in flexible manufacturing system.

\section{REFERENCES}

[1] H.H. Adelsberger and J.J. Kanet, "The Leitst and - a new tool for computer integrated manufacturing," Proceedings of the Third ORSA/TIMS Conference on Flexible Manufacturing Systems, Pp.253-258, 1989.

[2] L.H. Avonts and L.N. Wassenhove, "The part mix and routing mix problem in FMS". International Journal of Production Research, 26, Pp.1891-1902, 1988.

[3] R. Akella, Y. Choong and S.B. Gershwin, "Performance of hierarchical production scheduling policy," IEEE Transactions on Components, Hybrids, and Manufacturing Technology, Pp.215-217, 1984.

[4] A.B. Barr and E.A. Feigenbaum, "The Handbook of Artificial Intelligence," Los Altos, California: William and Kaufmann Inc., Vol. 1, Pp.343-348, 1981.

[5] A. Devikar, N. Garge, R. Welekar, K. Vasudevan and E. Williams, "Evaluating the Performance of a Complex Power and Free Conveyor System in a Flexible Manufacturing Environment,” Piscataway, New Jersey: Institute of Electrical and Electronics Engineers, Pp.1574-1583, 2010.

[6] G. Drake, J.S. Smith and B.A. Peters, "Simulation as a Planning And Scheduling Tool for Flexible Manufacturing Systems," Washington, DC: Institute of Electrical and Electronics Engineers Computer Society, Pp. 805-812, 1995.

[7] C. McLean and S. Leong, “The Expanding Role of Simulation in Future Manufacturing," Piscataway, New Jersey: Institute of Electrical and Electronics Engineers, Pp.1478-1486, 2001.

[8] O.D. Quiroga, L.M. Ciorciari and G.H. Rossetti, "Formulation of Simulation Models for Flexible Manufacturing Systems," 19th International Conference on Production Research, August 31, 2011.

[9] H. Tempelmeier and H. Kuhn, "Flexible Manufacturing Systems," Hoboken, New Jersey: John Wiley \& Sons, 1993.

[10] P. Udhayakumar and S. Kumanan, "Task Scheduling of AGV in FMS using Non-traditional Optimization Techniques,” International Journal of Simulation Modeling, Vol.9, No.1, Pp. 28-39, 2010.

[11] S. Wadhwa, A. Singholi and A. Prakash, "Simulation Modeling of Control Strategies in Flexible Manufacturing System,” Global Journal of Enterprise Information System, Vol.1, No.1, Pp.87-93, 2009.

[12] O.A. Joseph and R. Sridharan, "Effect of Part Launching Decisions on the Performance of a Flexible Manufacturing System: A Simulation Study,” Piscataway, New Jersey: Institute of Electrical and Electronics Engineers, Pp.1744-1748, 2008. 